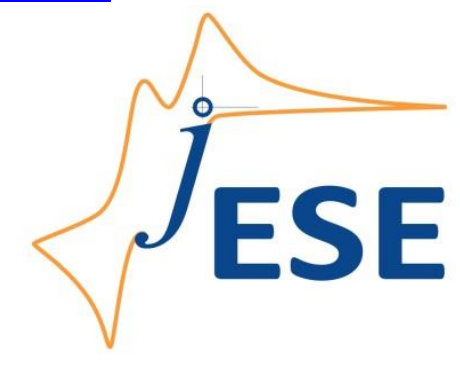

Open Access : : ISSN 1847-9286

www.jESE-online.org

Original scientific paper

\title{
Inhibitory action of Vernonia amygdalina extract (VAE) on the corrosion of carbon steel in acidic medium
}

\author{
Olamide Olawale ${ }^{1, \bowtie}$, Adeolu Adesoji Adediran², Segun Isaac Talabi ${ }^{3}$, \\ Geraldine Chika Nwokocha ${ }^{1}$, Alewo Opuada Ameh ${ }^{4}$ \\ ${ }^{1}$ Department of Chemical Engineering, College of Science and Engineering, Landmark University, \\ Omu-Aran, Kwara State, Nigeria \\ ${ }^{2}$ Department of Mechanical Engineering, College of Science and Engineering, Landmark University, \\ Omu-Aran, Kwara State, Nigeria \\ ${ }^{3}$ Department of Materials and Metallurgical Engineering, University of Ilorin, Ilorin, Nigeria \\ ${ }^{4}$ Chemical Engineering Department, Ahmadu Bello University, Zaria, Nigeria.; \\ ${ }^{\square}$ Corresponding authors E-mail: lamstock2@yahoo.com; olawale.olamide@Imu.edu.ng
}

Received: November 2, 2016; Revised: August 8, 2017; Accepted: August 9, 2017

\begin{abstract}
This study investigates the inhibition potential of Vernonia amygdalina stem extract (VAE) on the corrosion of mild carbon steel immersed in $1 \mathrm{M} \mathrm{HCl}$ solution containing various concentrations of the inhibitor. The corrosion rate and inhibition efficiency were evaluated using mass loss and adsorption techniques. The results revealed that VAE efficiently inhibits the corrosion rate of mild carbon steel immersed in the acidic medium. The concentration of $0.6 \mathrm{~g} / \mathrm{L}$ provides the highest inhibition efficiency of $78.1 \%$. The adsorption process was consistent with the physisorption mechanism and obeyed the Langmuir isotherm. The functional groups responsible for inhibition were identified using Fourier-transformed infrared (FTIR) spectra. The surface morphology of the corroded samples examined with scanning electron microscopy (SEM) revealed the presence of protective oxide layer. Inhibition efficiency was found dependet on the presence of oxalate, phytate, tannins, saponins and flavonoids in the VAE. It has been concluded that $V A E$ is safe, cheap and efficient corrosion inhibitor for mild carbon steel.
\end{abstract}

\section{Keywords}

Phytochemical; Vernonia amygdalina stem extract; Mild steel degradation; Inhibition efficiency; hydrochloric acid

\section{Introduction}

Corrosion is gradual deterioration of materials generated by their chemical interaction with the environment [1]. The corrosion of metal and alloy structures can be disastrous leading to economic 
loss in terms of repair, replacement, safety and environmental pollution. Mild steel has gain wide industrial application because of its excellent mechanical properties and low cost. This material, however, is prone to corrosion when exposed to the action of either bases or acids in the industries.

The use of inhibitors is one of the most practical methods for protecting materials against corrosion, especially in acid descaling bathes, and preventing not only the metal dissolution but also acid consumption. Inhibitors protect the metals by effectively adsorbing on their surfaces and blocking the active sites for metal dissolution and hydrogen evolution, respectively. In such a way, metal corrosion in aggressive environments becomes hindered [2]. The environmental toxicity of some inhibitors has led researchers to investigate the use of green and agro based materials as the alternatives to inorganic substances. These organic materials are biodegradable, cheaper and ecofriendly since they do not contain heavy metals or other toxic compounds [3]. They function via adsorption of the molecules on the metal surface creating a barrier to corrosion attack.

Green inhibitors from many plants have been investigated and reported by several authors as materials having the potential to reduce metal dissolution in various aggressive acids. Such plants include Jatropha curcas [4-6], Tithonia diversifolia [7], Carica papaya [8], Isertia coccinea [9], Telfaria occidentalis [10], Rice husk [11], Nicotiana tabacum [12], Water hyacinth [13], Moringa oleifera [14], Curcuma longa [15], Azadirachta indica [16], Phyllanthus amarus [17] and Bitter leaf [18]. It has been reported that the extract from these plants contained tannin and saponins that contribute to the inhibitory action via physical adsorption mechanism [19]. The protonated species are often adsorbed at the cathodic sites of the metal surface and retard hydrogen evolution reaction [20]. This was probably responsible for the pronounced cathodic inhibiting effect of $G$. africana observed at the ambient temperature $\left(30^{\circ} \mathrm{C}\right)$.

Plants leaves, especially bitter leaf (BF) has been reported to contain chlorophylls and carotenoids, phenols, alkaloids and terpenoids which are constituents of most organic inhibitors [21-23]. Omotosho and Ajayi [3] used the gasometric technique and reported the inhibitive effect of bitter leaf extract on environmentally assisted cracking of Al-alloy in $2.0 \mathrm{M}$ hydrochloric $(\mathrm{HCl})$ at the ambient temperature. Additionally, Ajayi et al [24] investigated the deterioration pattern and corrosion rate of the mild steel in $2 \mathrm{M} \mathrm{H}_{2} \mathrm{SO}_{4}$ at $333 \mathrm{~K}$ and related it with the concentration of $\mathrm{BF}$ extract.

Vernonia amygdalina (VA) (botanical name of BF) is a common plant largely available in all geopolitical zones of Nigeria, especially the south-western part of Nigeria. Hence, the use of BF as corrosion inhibitors $(\mathrm{Cl})$ constitutes one way to mitigate corrosion rate, protects metal surfaces against corrosion and preserves industrial facilities [25]. The present work reports the inhibitory action of VAE (extract from VA stem) on the mild steel corrosion in $1 \mathrm{M}$ hydrochloric acid. It is noteworthy, that chloride ions present in the media under investigation have the tendency to be specifically adsorbed on metal surfaces. They facilitate adsorption of protonated inhibitor species by forming intermediate bridges between the metal surfaces and the inhibitor [26].

\section{Experimental technique}

\section{Preparation of mild steel}

The composition of the mild steel used in this experiment is presented in Table 1.

The $0.2 \mathrm{~cm}$ thick steel was mechanically cut into coupons of dimensions $5.0 \times 4.0 \mathrm{~cm}$. The surface treatment was done by degreasing the coupons using absolute ethanol, followed by drying in acetone. The samples so prepared were stored in the desiccator. The experiments were carried out under non-stirred and aerated conditions. 
Table 1. Composition of mild steel

\begin{tabular}{cc}
\hline Element & Content, \%wt. \\
\hline $\mathrm{C}$ & 0.2 \\
$\mathrm{P}$ & 0.024 \\
$\mathrm{Si}$ & 0.003 \\
$\mathrm{Mn}$ & 0.35 \\
$\mathrm{Fe}$ & 99.4 \\
\hline
\end{tabular}

Preparation of plant extract

$4 \mathrm{~kg}$ of fresh stems (Vernonia amygdalina) was sun dried for 28 days to completely remove the moisture content. Stems were then grounded into powder and sieved. $20 \mathrm{~g}$ of the powdered material was soaked in $700 \mathrm{ml}$ ethanol solution and kept inside a desiccator to prevent evaporation for a period of $24 \mathrm{~h}$ and filtered. Finally, the filtrate was heated at $80^{\circ} \mathrm{C}$ for 25 minutes inside a rotary evaporator in order to remove the ethanol. FTIR (Shimadzu, model IR AFFINITY, IS FTIR) was used to determine the functional groups responsible for the inhibition.

\section{Corrosion rate and inhibition efficiency measurement}

For the corrosion experiment, the mild steel coupons were totally immersed in $250 \mathrm{ml}$ capacity beakers containing $100 \mathrm{ml}$ of $1 \mathrm{M} \mathrm{HCl}$ solution. The initial weight of the mild steel coupons was taken before immersion in the acid solution with and without the addition of inhibitor. To achieve total coverage, the coupons were suspended in the beaker with the aid of rod and hook. The quantities of inhibitor ranging from $0.2-0.8 \mathrm{~g} / \mathrm{L}$ were added to the corrosion medium. The experiment was conducted at ambient temperature during $360 \mathrm{~h}$ (15 days). The weight of the specimens after immersion was taken every $72 \mathrm{~h}$ ( 3 days) using electronic weighing balance ( $\mathrm{HX} 302 \mathrm{~T}$ with $0.01 \mathrm{~g}$ accuracy). Prior to weight measurements, the samples were cleaned with distilled water and dried with acetone to remove the corrosion products. The experiment was carried out in duplicate to ensure reproducibility. The corrosion rate (CR) and inhibition efficiency (IE) were calculated using equations (1) and (2)

$$
\begin{aligned}
& \mathrm{CR}=\frac{\Delta W}{A T}=\frac{W_{1}-W_{2}}{A T} \\
& I E / \%=\left(\frac{\mathrm{CR}_{1}-\mathrm{CR}_{2}}{\mathrm{CR}_{1}}\right) \times 100
\end{aligned}
$$

where $W_{1}$ is the mild steel weight before immersion, $W_{2}$ is the mild steel weight after immersion, $A$ is the surface area of the coupon in $\mathrm{cm}^{2}, T$ is the period of immersion in $\mathrm{h}, \mathrm{IE} / \%$ is inhibition efficiency, $C R_{1}$ is corrosion rate of mild steel coupons in the absence of inhibitors and $C R_{2}$ is the corrosion rate of mild steel coupons in the presence of concentration of inhibitors.

\section{Surface Examination}

The surface features of the mild steel coupons were examined with SEM before and after exposure to $\mathrm{HCl}$ solution for $360 \mathrm{~h}$ (15 days) in the presence and absence of inhibitor, respectively.

\section{Results and discussion}

Phytochemical screening and inhibitive ability of VAE

The phytochemical screening of VAE indicates compounds such as tannins, saponins and alkaloids [27]. The weight percents of these compounds were reported by Ayeni and co-workers [24]. The assessment of the inhibitive property of VAE was investigated through the weight loss technique. 
Figure 1 shows the corrosion rate $\left(\mathrm{g} / \mathrm{cm}^{2} \mathrm{~h}\right)$ of mild steel in $1 \mathrm{M} \mathrm{HCl}$ in the presence and absence of various concentrations of inhibitor with exposure time (days). The corrosion rate was found to decrease with increasing concentration of VAE in the corrosion medium. The improved resistance to corrosion is due to adsorption of the constituents of the extract on the surface of the mild steel [28]. Moreover, a significant retardation in the rate of corrosion can be observed after $288 \mathrm{~h}$ (12 days) and the effect is more pronounced with the addition $0.8 \mathrm{~g} / \mathrm{L}$ of VAE. The corrosion rate diminished due to the increased thickness of the protective oxide layer.

Direct relationship between inhibition efficiency and exposure time varies for different VAE concentrations as shown in Figure 2. The inhibitor efficiency increases with increased exposure time. The highest efficiency of $78.12 \%$ was achieved in the corrosion medium containing $0.6 \mathrm{~g} \mathrm{~L}^{-1} \mathrm{VAE}$ after 12 days of exposure. Irrespective of the amount of VAE in the acidic medium, its efficiency began to decline after 6 days.

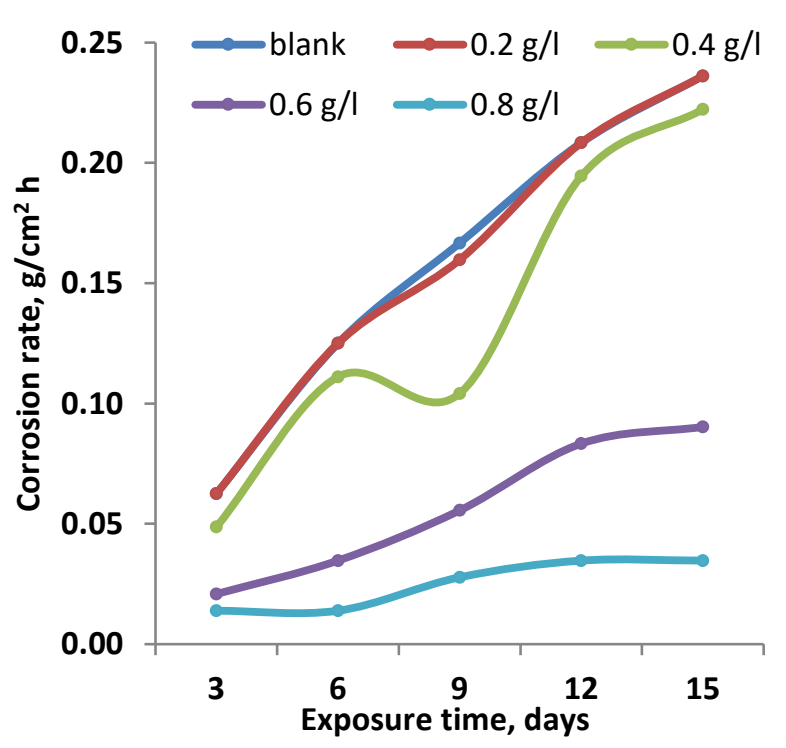

Figure 1. Variation of the corrosion rate with exposure time

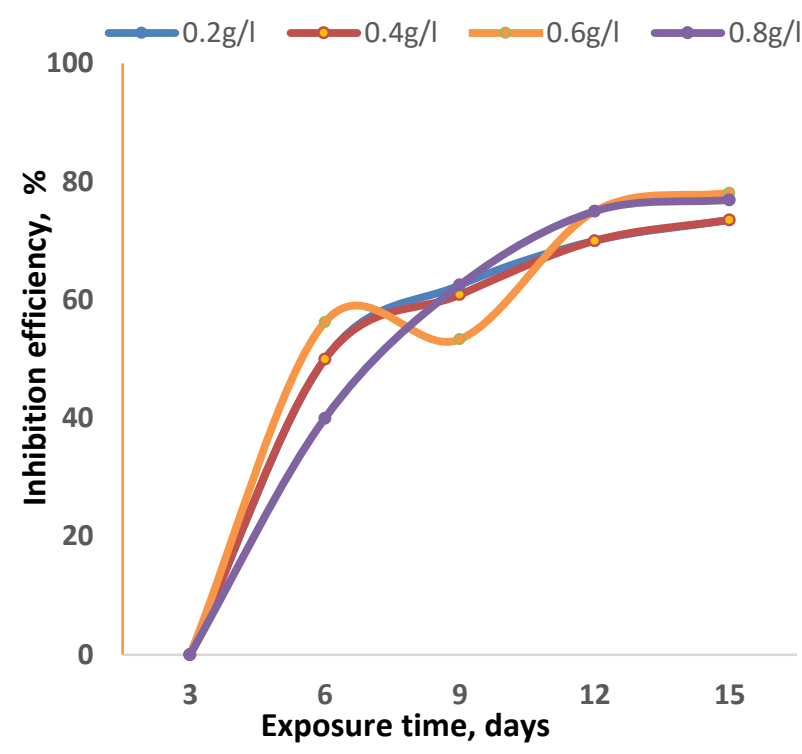

Figure 2. Variation of inhibition efficiency with exposure time

\section{Adsorption isotherms}

Adsorption is usually modeled by Langmuir, Frumkin, Freundlich, Flory-Huggins, Temkin or Bockris-Swinkles adsorption isotherms [30]. Here, equation (3) was used to calculate degree of surface coverage $(\theta)$ for the different concentrations of VAE. In this study, Langmuir model was adopted to determine the adsorption isotherm according to equation (4).

$$
\begin{aligned}
& \mathrm{IE}=\theta \times 100 \\
& \frac{c}{\theta}=\frac{1}{K_{\text {ads }}}+c
\end{aligned}
$$

In equation (4), $c$ is inhibitor concentration and $K_{\text {ads }}$ is equilibrium constant of the inhibitor adsorption. To determine $K_{\mathrm{ads}}$, the value of $c / \theta$ was plotted against $c$ giving the linear line with the root mean square value of 0.998 (Figure 3). According to the equation (4), the inverse of the intercept gives the equilibrium adsorption constant, $K_{\text {ads. }}$. The inhibition process may take place through either chemical adsorption or physical adsorption of the inhibitor's molecules [15]. To ascertain this and according to other researchers' reports [31-32], $K_{\text {ads }}$ can be related to the adsorption free energy ( $\left.\Delta G_{\text {ads }}\right)$ using the equation (5): 


$$
K_{\mathrm{ads}}=\left(\frac{1}{55.5}\right) \exp \left(\frac{-\Delta G_{\mathrm{ads}}}{R T}\right)
$$

In the equation (5), 55.5 is water concentration, $\Delta G_{\text {ads }}$ is free energy of adsorption, $R$ is the universal gas constant and $T$ is temperature.

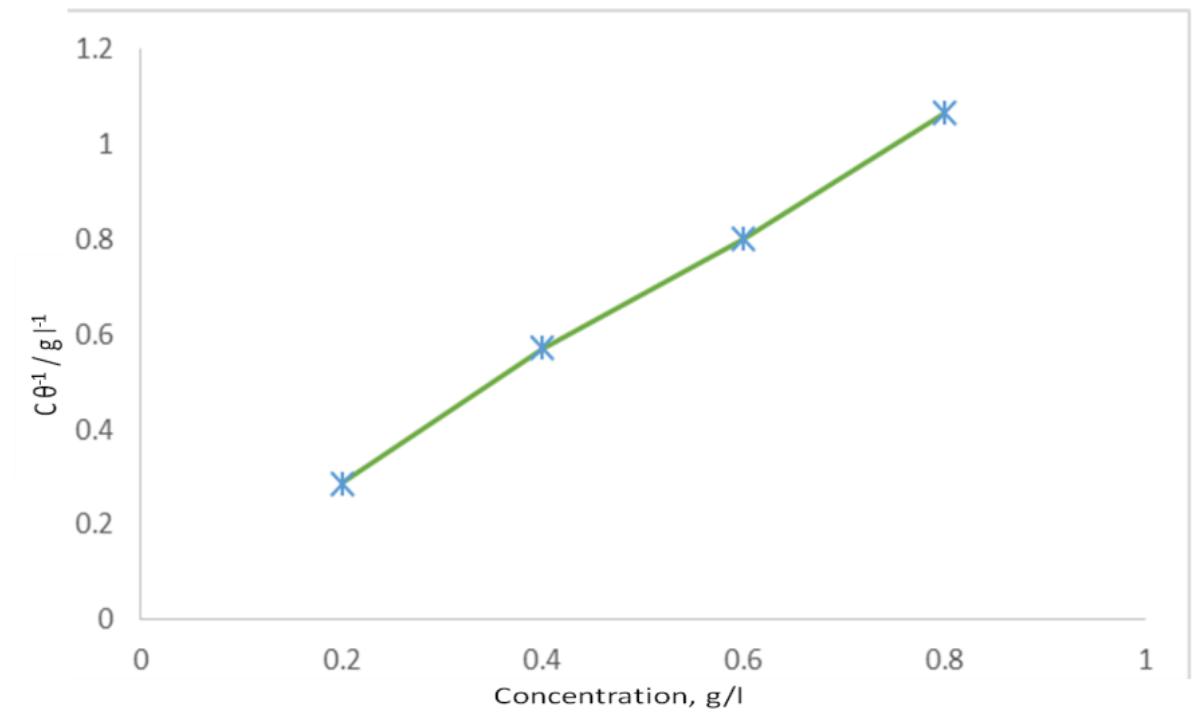

Figure 3. Langmuir adsorption plot for mild steel in $1 \mathrm{M} \mathrm{HCl}$ containing different concentrations of VAE at $30^{\circ} \mathrm{C}$

Table 2 shows the Langmuir adsorption parameters obtained for the VAE at $30{ }^{\circ} \mathrm{C}$

Table 2. Some parameters from Langmuir isotherm

\begin{tabular}{cccccc}
\hline Methods & Temperature & $\Delta G_{\text {ads }} / \mathrm{KJ} \mathrm{mol}^{-1}$ & Slope & $K_{\text {ads }} / \mathrm{Lg}^{-1}$ & $\mathrm{R}^{2}$ \\
\hline Weight loss & $30^{\circ} \mathrm{C}$ & -18.349 & 0.257 & 26.247 & 0.998 \\
\hline
\end{tabular}

$\mathrm{R}^{2}=$ correlation coefficient

Free energy of adsorption, $\Delta G_{\text {ads, }}$ obtained from the equation (5) shows a negative value suggesting that adsorption process of the VAE was spontaneous. According to Awe et al. [19], if $\Delta G_{\text {ads }}$ was around $-20 \mathrm{KJ} / \mathrm{mol}$ or less, the adsorption is consistent with physisorption, while for $\Delta G_{\text {ads }}$ around $-40 \mathrm{KJ} / \mathrm{mol}$ or higher, the adsorption is consistent with chemisorption mechanism. Hence, it seems that VAE adsorption process in the present corrosive medium is physisorption. This is in full agreement with observations of other authors $[18,28,30]$. The strength of the adsorption bond depends upon the electron density of the functional group donor atom and the polarizability of the group [33]. The replacement of $\mathrm{H}$ atom attached to the $\mathrm{C}$ in the ring by a substituent group $\left(\mathrm{NH}_{2}\right.$, $\mathrm{OH}, \mathrm{NH}, \mathrm{NO}_{2}, \mathrm{CHO}$, or $\mathrm{COOH}$ ) improves inhibition.

FT-IR spectra shown in Figures 4 and 5 are plots of percentage of intensity (relative abundance of each functional group) and the frequency values given in $\mathrm{cm}^{-1}$, depicting the surface coverage of each functional group in the inhibition process.

Thus, the peak at $2113 \mathrm{~cm}^{-1}$ in Figure 5, which has already been attributed to hydroxyl (OH) group [34], confirms the presence of large amount of saponin compound in VAE. The inhibitive ability of inhibitors depends greatly on their phytochemical constituents. Compounds such as alkaloids, saponins, tannins and flavonoids have been reported to have inhibitory property [27,29]. For example, the presence of tannins may lead to the formation of passivating layer of tannates on the carbon steel surfaces. In addition, $\mathrm{OH}$ groups around the molecules can form strong complexes which block the generated micro anodes formed in the contact with corrosion medium [29]. 


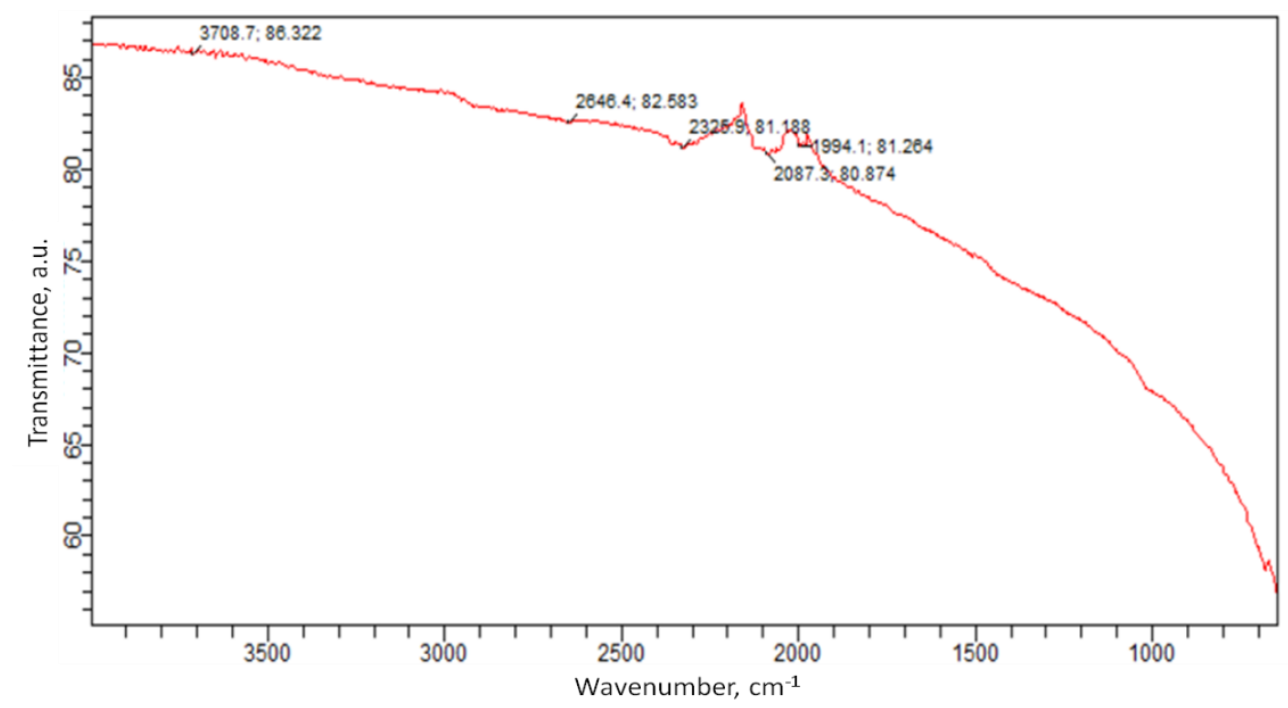

Figure 4. FT-IR spectra of mild steel immersed in $1 \mathrm{M} \mathrm{HCl}$ without VAE inhibitor

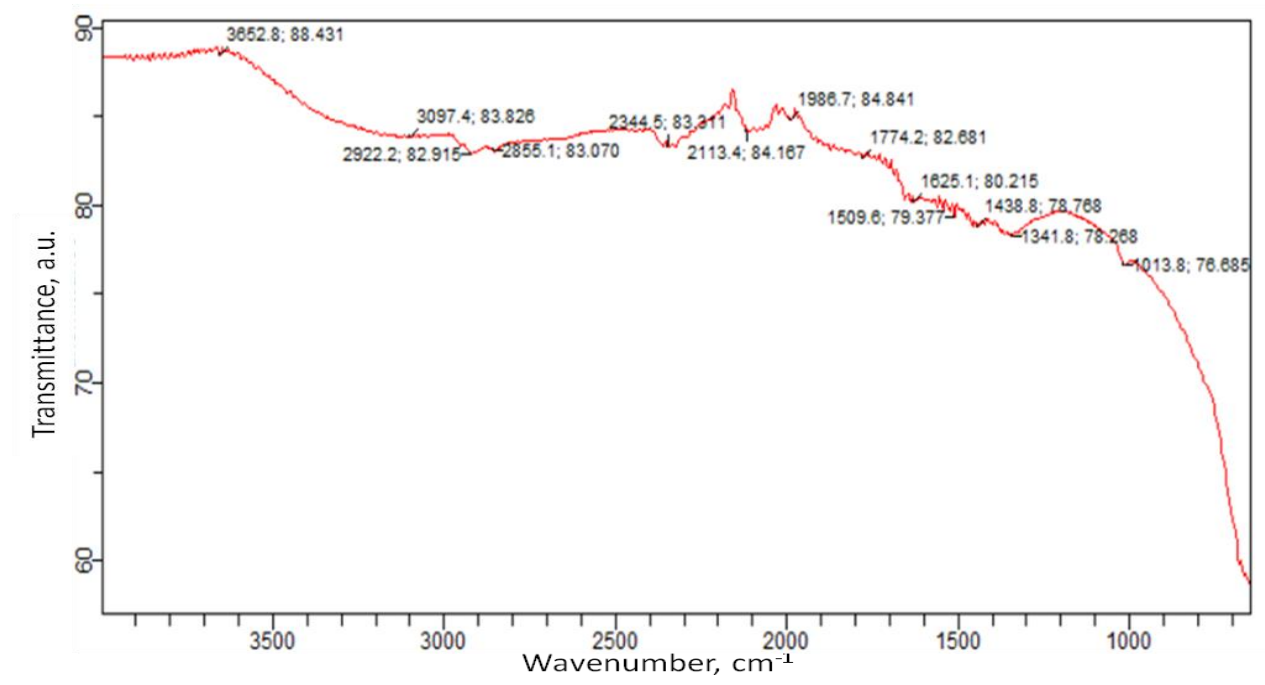

Figure 5. FT-IR spectra of mild steel immersed in $1 \mathrm{M} \mathrm{HCl}$ containing $0.8 \mathrm{~g} / \mathrm{L}$ of VAE inhibitor

\section{Surface morphology examination}

To justify the observations, the surface morphology of the corroded samples in the presence and absence of VAE was examined. Figure 6 shows that the mild steel sample immersed in $0.1 \mathrm{M} \mathrm{HCl}$ without inhibitor corroded more than the mild steel sample exposed to degradation in the presence of VAE inhibitor.
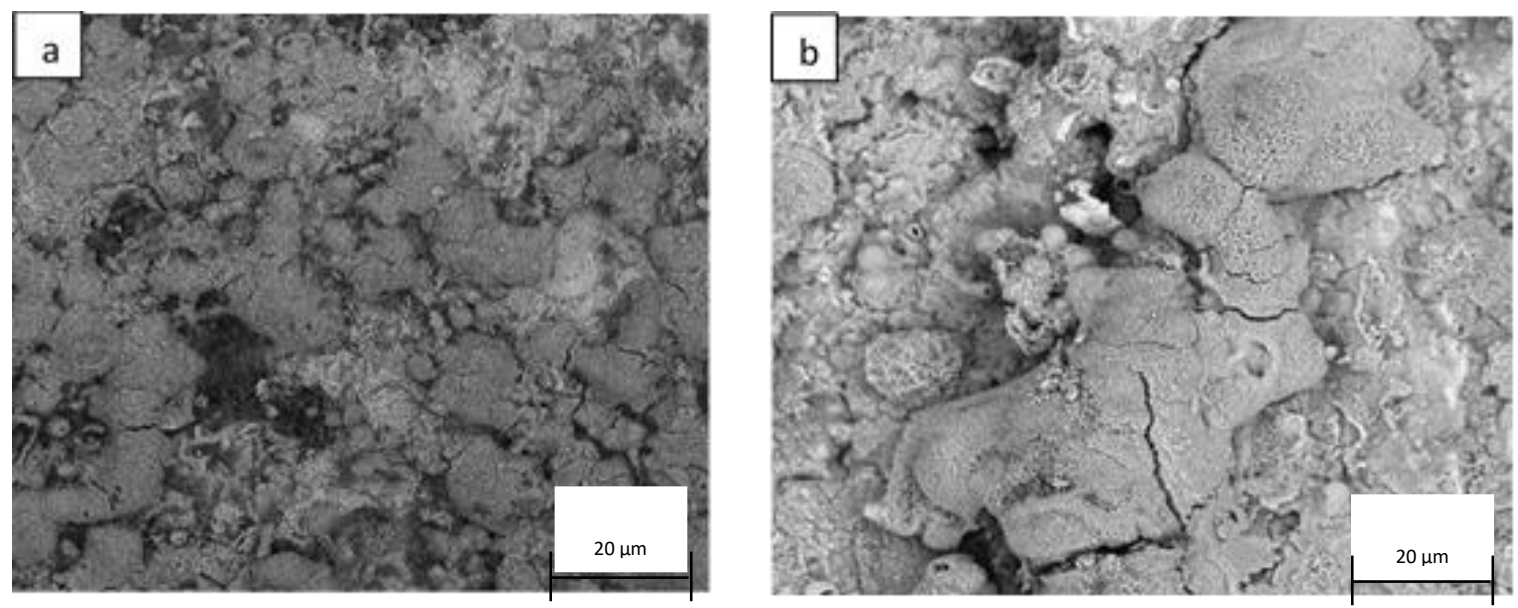

Figure 6. SEM images of mild steel coupon in $1 \mathrm{M} \mathrm{HCl}$ solution after $360 \mathrm{~h}$ of total immersion in absence (a) and presence of $0.8 \mathrm{~g} / \mathrm{L} V A E$ inhibitor (b) 
The white patches on the surface of the samples represent the protective oxide. Typically, its formation was partly dependent on the inhibitor chemical composition and molecular structure, and the substrate charged surface (i.e. the oxide affinity for the metal surface) [35].

\section{Conclusion}

In agreement with typical characteristic of all organic inhibitors, VAE shows an outstanding ability to provide improved corrosion resistance of mild steel in acidic medium $(\mathrm{HCl})$. The inhibitive ability of VAE depends on protective oxide layer formed at the mild steel surface by adsorption mechanism due to the presence of tannin and saponin. The adsorption parameters obeyed the Langmuir model. The value of adsorption free energy implies a spontaneous process consistent with physical adsorption mechanism. Consequently, VAE can be recommended for use in industrial processes to reduce metal dissolution in acidic media. Moreover, being a cheap, non-toxic and eco-friendly compound, VAE can easily substitute most of the inorganic synthetic inhibitors.

\section{References}

[1] P. Neha, A. Shruti, S. Pallav, Chinese Journal of Engineering. doi.org/10.1155/2013/748186

[2] S. Bhat, V.K. Sharma, S. Thomas, P.F. Anto, S.K. Singh, Material performance 50 (2011) 50-53.

[3] O. O, Ajayi, O. A. Omotosho, O. Vincent, V. O. Ifepe, Journal of Materials and Environmental Science 2 (2011) 186-195.

[4] J. K. Odusote, O. M. Ajayi, Journal of Electrochemical Science and Technology 4 (2013) 81-87.

[5] O. Olawale, F. A. Oyawale, A. A. Adediran, A. S. Obafemi, Fascicula de Inginerie 23 (2016) 228-238.

[6] K .K. Alaneme, S. J. Olusegun, Leonardo Journal of Sciences 20 (2012) 59-70.

[7] E. E. Ebenso, U. J. Ekpe. West African Journal of Biological and Applied Chemistry 41 (1996) 21-27.

[8] M. Lebrini, F. Robert, P.A. Blandinières, C. Roos. International Journal of Electrochemical. Science 6 (2011) 2443- 2460.

[9] E. E. Oguzie. Pigment and Resin Technology 34 (2005) 321-326.

[10] K. K. Alaneme, Y. S. Daramola, S. J. Olusegun, A. S. Afolabi, International Journal of Electrochemical Science 10 (2015) 3553- 3567.

[11] E. F. Olasehinde, S. J. Olusegun, A. S. Adesina, S. A. Omogbehin, H. Momoh-Yahayah, Natural Sciences $11(2013)$ 83-90.

[12] D .T. Oloruntoba, J. A. Abbas, S. J. Olusegun, Proceedings of $4^{\text {th }}$ West Africa Built Environment Research (WABER), Abuja, Nigeria, 24-26 July (2012) 1131-1140.

[13] A. Singh, I. Ahamad, D. K. Yadav, V. K. Singh, M. A. Quraishi, Chemical Engineering Communications 199 (2011) 63-77.

[14] N. I. Kairi, J. Kassim, International Journal of Electrochemical Science 8 (2013) 7138-7155.

[15] U. J. Ekpe, E. E. Ebenso, U. J. Ibok, Journal of the West African Science Association 37 (1994) 13-30.

[16] P. C. Okafor, M. E. Ikpi, I. E. Uwah, E. E. Ebenso, U. J. Ekpe, S. A. Umoren, Corrosion Science 50 (2008) 2310-2317.

[17] C. A. Loto, Corrosion Prevention and Control 50 (2003) 43-49.

[18] A. Y. EL-Etre, Applied Surface Science 252 (2006) 8521-8525.

[19] I. C. Awe, A. S. Abdulrahaman, H. K. Ibrahim, A. G. Karrem, S. M. Adams. American Journal of Materials Engineering and Technology 3 (2015) 1-45.

[20] K. Kumar, M. Pillai, G. Thusnavia, Journal of Materials, Science and Technology 27 (2011) 1143-2011.

[21] U. Udochukwu, F. I. Omeje, I. S. Uloma, F. D. Oseiwe, American Journal of Research Communication 3 (2015) 225-235.

[22] N. O. A. Imaga, D. O. Bamigbetan, International Journal of Nutrition and Metabolism 5 (2013) 22-27.

[23] H. Gerengi, H. I. Sahin, Industrial and Engineering Chemistry Research 51 (2012) 780-788.

[24] F. A. Ayeni, I. A. Madugu, P. Sukup, A. P. Ihom, O. O. Alabi, R. Okara, M. Abdulwahab, Journal of Minerals \& Materials Characterization and Engineering 1 (2012) 667-670.

[25] O. A. Omotosho, O. O. Ajayi, TBJ. Eng. Sci, 44 (2012) 77-92.

[26] E. E. Oguzie, Materials, Chemistry and Physics 87 (2004) 12-17. 
[27] S. J. Olusegun, B. A. Adeiza, K. I. Ikeke, M. O. Bodunrin, Journal of Emerging Trends in Engineering and Applied Sciences 4 (2013) 138-143.

[28] G. E. Debi, H. Esah, I. Mohammed, A. S. Abdulraham, M. Aminu, Australian Journal of Basic and Applied Sciences 7 (2013) 257-263.

[29] A. N. Lebe, I. O. Owate, E. E. Oguzie, International Journal of Materials Engineering 4 (2014) 171-179.

[30] E. E. Oguzie, Corrosion Science 49 (2007) 1527-1539.

[31] O. O. Obiukwu, I. O. Opara, B. C. Oyinna, The Pacific Journal of Science and Technology 14 (2013) 3135.

[32] A. Rani, B. B. J. Basu, International Journal of Corrosion (2012) doi:10.1155/2012/380217

[33] F. S. De Souza, A. Spinelli, Corrosion Science 51 (2009) 642-649.

[34] M. A. Ameer, A. M. Fekry, Progress in Organic Coatings 71 (2011) 343-349.

[35] A. Singh, S. Eno, E. E. Ebenso, M. A. Quraishi, International Journal of Corrosion (2012) 1-20, doi:10.1155/2012/897430

(C2017 by the authors; licensee IAPC, Zagreb, Croatia. This article is an open-access article distributed under the terms and conditions of the Creative Commons Attribution license (http://creativecommons.org/licenses/by/4.0/) 